\title{
Erratum to: Molecular mechanisms of gravity perception and signal transduction in plants
}

\author{
Yaroslav S. Kolesnikov ${ }^{1}$ • Serhiy V. Kretynin ${ }^{1}$ - Igor D. Volotovsky ${ }^{2}$. \\ Elizabeth L. Kordyum ${ }^{3}$ • Eric Ruelland ${ }^{4,5}$ • Volodymyr S. Kravets ${ }^{1}$
}

Published online: 5 January 2016

(C) Springer-Verlag Wien 2016

\section{Erratum to: Protoplasma \\ DOI 10.1007/s00709-015-0859-5}

Unfortunately, the original publication of this article contains errors. In table 1, the phrase "Localized under amyloplasts" should be changed to "Associated with amyloplasts". In "Protein Phosphorylation/

The online version of the original article can be found at http://dx.doi.org/ 10.1007/s00709-015-0859-5.

Volodymyr S. Kravets

kravets@bpci.kiev.ua

Igor D. Volotovsky

volot@biobel.bas-net.by

Elizabeth L. Kordyum

cellbiol@ukr.net

Eric Ruelland

eric.ruelland@u-pec.fr

1 Department of Molecular Mechanisms of Cell Metabolism Regulation, Institute of Bioorganic Chemistry and Petrochemistry, National Academy of Sciences of Ukraine, Murmanska St., 1, Kiev 02094, Ukraine

2 Institute of Biophysics and Cell Engineering, National Academy of Sciences of Belarus, Academycheskaya St., 27, Minsk 220072, Belarus

3 Department of Cell Biology and Anatomy, Institute of Botany, National Academy of Sciences of Ukraine, Tereschenkivska St., 2, Kyiv 01004, Ukraine

4 Université Paris-Est Créteil, Institut d'Ecologie et des Sciences de l'Environnement, Paris, France

5 Institut d'Ecologie et des Sciences de l'Environnement, Centre National de la Recherche Scientifique, Paris, France dephosphorylation" section, the citation "Clore et al., 2003" should be deleted from the complex (Clore et al., 2003; Liu et al., 2009). In the middle of the same paragraph, the citation "Clore et al., 2003" should be deleted from the complex (Chang, Kaufman, 2000; Clore et al., 2003), and the citation (Clore at al., 2003) at the end of the same paragraph should be also changed to (Chang et al., 2003) and lost citation "Chang SC, Cho MH, Kim SK, Lee JS, Kirakosyan A, Kaufman PB (2003) Changes in phosphorylation of 50 and $53 \mathrm{kDa}$ soluble proteins in graviresponding oat (Avena sativa) shoots Journal of Experimental Botany 54:1013-1022" should be added to the list of references. In "Protein Phosphorylation/dephosphorylation" section, at the beginning of the first paragraph in sentence "The relatively long time $(75 \mathrm{~min})$ needed for the MAP kinase activity to rise suggests that it only acts after the onset of gene expression or as the result of auxin transport/action" the phrase "or as the result of auxin transport/action" should be deleted. In section "Phosphoinositide-specific phospholipase $C$ " at the beginning of the second paragraph the sentence "The increase in $\mathrm{IP}_{3}$ in response to gravity is independent on auxin transport" should be changed to "Changes in $\mathrm{InsP}_{3}$ may precede auxin redistribution". In the sentence "Results of pharmacological studies show that $\mathrm{IP}_{3}$ action in gravity response is calcium mediated and the second phase of calcium increase is dependent on PI-PLC production of $\mathrm{IP}_{3}$ (Perera et al. 2001; Plieth and Trewavas 2002; Toyota et al. 2013a) at the end of the 3 paragraph the "Perera et al. 2001" citation should be changed to "Perera et al. 2006". In table 3, in the line containing an information about exogenous application of $\mathrm{H}_{2} \mathrm{O}_{2}$ to the lower side of pulvinus the word "no" should be replaced with "+" and description "no, No effect" under the table should be deleted. 